\title{
TOWARDS OPERATIONAL SEA ICE TYPE RETRIEVAL USING L-BAND SYNTHETIC APERTURE RADAR
}

\author{
Suman Singha* \\ Remote Sensing Technology Institute (IMF) \\ German Aerospace Center (DLR) \\ Henrich Focke Str. 4, 28199, Bremen, Germany
}

A. Malin Johansson, Anthony P. Doulgeris

\author{
UiT The Arctic University of Norway \\ Department of Physics and Technology \\ NO-9037, Troms $\varnothing$, Norway
}

\begin{abstract}
Operational ice services around the world have recognized the economic and environmental benefits that come from the increased capabilities and uses of space-borne Synthetic Aperture Radar (SAR) observation system. The two major objectives in SAR based remote sensing of sea ice is on the one hand to have a large areal coverage, and on the other hand to obtain a radar response that carries as much information as possible. Although until now, L-Band SAR sensors are rarely used in an operational context, it offers greater capabilities for sea ice type retrieval and is more robust during the melt season compared to higher frequency bands. With the help of JAXA's ALOS-2 PALSAR-2 sensor, we are able to explore the potential of polarimetric L-band acquisitions for sea ice analysis and classification in an operational environment. In this study we investigated the incidence angle related variation on the L-band backscatter and recommended optimal scenarios for Artificial Neural Network based sea ice type retrieval schemes.
\end{abstract}

Index Terms - Sea Ice Type; Feature Extraction; Polarimetry; ALOS-2; TanDEM-L; Landsat-8

\section{INTRODUCTION}

Synthetic Aperture Radar (SAR) images are, due to their ability to penetrate clouds and to operate without daylight, used operationally to monitor the sea ice in both the Arctic and the Antarctic regions. The monitoring has primarily relied on C-band SAR starting with the ERS-1/2 and followed by ENVISAT and RADARSAT- $1 / 2$ and lately with the Sentinel1 constellation, without exploiting polarimetric capabilities. Whereas single-polarimetric acquisitions which are currently being used in operational scenarios, offer a wide coverage on the ground, dual polarimetric or even better fully polarimetric data offer a higher information content which allows for a more reliable automated sea ice type retrieval over the Arctic

\footnotetext{
*Corrosponding Author E-mail: Suman.Singha@dlr.de. The research is funded through EMS-II and CIRFA (grant number 237906). ALOS-2 PALSAR-2 scenes were provided by JAXA under the 4th Research Announcement program (PI: Torbjørn Eltoft, ALOS PI No.1199).
}

region. For the maritime industry detection and monitoring of safe passages are important and this includes identification of open water and thinner sea ice areas that enables energy efficient passage as well as identification of deformed sea ice areas such as ridges and converging zones that will impede progress resulting in higher fuel cost.

L-band SAR images are not regularly used operationally but investigations have been made by e.g. [1] into it's usability for operational services. Multiple studies have shown that L-band SAR can provide better contrast between different sea ice types and can provide complimentary information [1, 2], such as detecting and separating deformed sea ice from the surrounding sea ice [2] and provide easier separation between first year ice (FYI) and multi-year ice (MYI) in the early and advanced melt season [2]. It was reported by [3] that L-band SAR could separate MYI among second year ice (SYI) during dry ice winter conditions. MYI is generally thicker and harder than FYI and a successful classification between the two is therefore beneficial in an operational scenario. In an another study L-band was found to be less sensitive to wet snow on top of the sea ice compared to X-and C-band in the beginning of the melt season. Based on the previous studies which used polarimetric L-band dataset, we can reasonably argue that polarimetric L-band SAR provides a significant amount of complimentary information for sea ice characterization within an operational environment. Furthermore, future L-band missions such as TanDEM-L and NISAR will offer the advantages of fully polarimetric acquisitions along with higher ground coverage to achieve a optimal scenario for L-band SAR based sea ice monitoring.

The ALOS-2 PALSAR-2 images used in this study were acquired from April 2015 until June 2015 and have an incidence angle (mid) range from $27.83^{\circ}$ to $39.05^{\circ}$. They overlap in space and time with two in-situ sea ice observation campaigns, the Norwegian Young Sea Ice Cruise (N-ICE2015) and PS92 Transitions in the Arctic Seasonal Sea Ice Zone (TRANSSIZ). Temperature records from N-ICE2015 show a range from $-25^{\circ} \mathrm{C}$ to $+2^{\circ} \mathrm{C}$ during the time of satellite image acquisitions. This enables us to investigate stability of different polarimetric parameters for different environmental 
Table 1. ALOS-2 used in this study. The images are High-sensitive Quad (HBQ) polarimetric images. The scenes centre incidence angle is presented.

\begin{tabular}{|c||c|c|c|c|c|c|}
\hline Datum & \# images & $\begin{array}{c}\text { Incidence } \\
\text { Angle }\end{array}$ & Beam & $\begin{array}{c}\text { Slant Rg./ } \\
\text { Az. Res. }\end{array}$ & $\begin{array}{c}\text { Footprint } \\
\text { Az } \times \text { Rg. }\end{array}$ & NESZ \\
\hline \hline $2015 / 03 / 30-2015 / 04 / 12$ & 6 & $36.55^{\circ}$ & FP6-6 & $5.1 \mathrm{~m} / 4.3 \mathrm{~m}$ & $70 \mathrm{~km} \times 42 \mathrm{~km}$ & $\begin{array}{c}-36.0 \mathrm{~dB}(\mathrm{HH}) \\
-46.0 \mathrm{~dB}(\mathrm{HV})\end{array}$ \\
\hline $2015 / 04 / 13-2015 / 04 / 26$ & 31 & $33.91^{\circ}$ & FP6-5 & $5.1 \mathrm{~m} / 4.3 \mathrm{~m}$ & $70 \mathrm{~km} \times 42 \mathrm{~km}$ & $\begin{array}{l}-36.0 \mathrm{~dB}(\mathrm{HH}) \\
-46.0 \mathrm{~dB}(\mathrm{HV})\end{array}$ \\
\hline $2015 / 04 / 27-2015 / 05 / 10$ & 24 & $31.14^{\circ}$ & FP6-4 & $5.1 \mathrm{~m} / 4.3 \mathrm{~m}$ & $70 \mathrm{~km} \times 42 \mathrm{~km}$ & $\begin{array}{l}-36.0 \mathrm{~dB}(\mathrm{HH}) \\
-46.0 \mathrm{~dB}(\mathrm{HV})\end{array}$ \\
\hline $2015 / 05 / 11-2015 / 05 / 24$ & 24 & $27.83^{\circ}$ & FP6-3 & $5.1 \mathrm{~m} / 4.3 \mathrm{~m}$ & $70 \mathrm{~km} \times 42 \mathrm{~km}$ & $\begin{array}{l}-36.0 \mathrm{~dB}(\mathrm{HH}) \\
-46.0 \mathrm{~dB}(\mathrm{HV})\end{array}$ \\
\hline $2015 / 05 / 25-2015 / 06 / 07$ & 23 & $39.05^{\circ}$ & FP6-7 & $5.1 \mathrm{~m} / 4.3 \mathrm{~m}$ & $70 \mathrm{~km} \times 42 \mathrm{~km}$ & $\begin{array}{c}-36.0 \mathrm{~dB}(\mathrm{HH}) \\
-46.0 \mathrm{~dB}(\mathrm{HV})\end{array}$ \\
\hline
\end{tabular}

conditions and different incidence angles for a comprehensive L-band SAR based sea ice type retrieval.

\section{DATASET}

The study area is located in the Arctic Ocean north of Svalbard, between $80^{\circ} \mathrm{N}$ to $84^{\circ} \mathrm{N}$ and $8^{\circ} \mathrm{W}$ to $25^{\circ} \mathrm{E}$. ALOS2 L-band SAR satellite images in High-sensitive Quad polarimetry (HBQ) mode were acquired to overlap with the NICE2015 sea ice drift campaign in spring and early summer of 2015 as well as PS92 TRANSSIZ in early summer 2015. During this time period the total snow and ice thickness measured with ground-based electromagnetic (EM) was found to be $1.6 \mathrm{~m}$ (N-ICE2015) and $1.8 \mathrm{~m}$ (TRANSSIZ) and airborne EM measurements was $1.7 \mathrm{~m}$ for both campaigns. The sea ice within the study areas was primarily a mixture of FYI and SYI [4] though areas of thinner sea ice types such as nilas, young grey ice and young white ice were observed. Presence of frost flowers were observed on the young ice during the entire N-ICE2015 drift study.

The dataset consists of satellite data with five different mean incidence angles, Table 1 The different incidence angles were pre-set in the Basic Observation Scenario by JAXA and each average incidence angle corresponds to fixed datum intervals. Each acquisition consists of one to six frames, where each frame corresponds to nominal acquisition length in the azimuth direction. In total 108 satellite images are used in this study and out of these 102 images are approximately equally distributed for the incidence angles of beams FP6-3, FP6-4, FP6-5 and PF6-7 (Table 1) and the remaining 6 images are taken with beam FP6-6. Furthermore spatially and temporally overlapping Landsat- 8 scene were collected for validation purpose.

\section{METHODOLOGY}

For the implementation of the feature extraction we used IDL. The neural network was based on the FANN library, programmed in $\mathrm{C}$, which was built into our IDL implementa- tion of the process chain. After feature extraction, the feature matrices were down-sampled by a user defined factor and rescaled to meet the requirements of the neural network input data range, resulting in an output classified image with dimension reduced by the user defined factor. The training and validation data are defined by small patches for each ice type. Those patches were determined by visual judgment of the polarimetric feature images in conjunction with in-situ measurements and ice charts provided by Norwegian Ice Services. The Artificial Neural Network (ANN) has been used for sea ice classification for X-, C- and L-band SAR images and the setup of the network is explained in [5, 6]. The ANN has already shown to produce high accuracy results for sea ice classification when a self-trained-validated classification is performed [5] and a comparison with spatially and temporally overlapping high resolution airborne laster scanner measurements confirmed high accuracy sea ice classification [6].

The incidence angle dependency for the different sea ice types as noted by several previous studies, e.g. [7, 8], meant that for this study one training and validation dataset for each different set of incidence angles was extracted. Thereafter we classify the sea ice in two different ways, firstly with an incidence angle dependent training and validation dataset (selftrained-validation) and secondly, we train the algorithm with one incidence angle dataset and validate it using another incidence angle dataset (cross-trained-validation). The classification results are also validated against overlapping optical Landsat-8 images (Fig. 11.

\section{RESULTS AND DISCUSSION}

The self-trained-validation is carried out for one scene for each incidence angle (IA) set (Fig. 2). As can be observed the classification accuracy for the self-training is above $92 \%$. The maximum accuracy was found on 3 April (IA: $36.55^{\circ}$ ) (Table 2) and the maximum inaccuracy was found on 18 May (IA: $27.83^{\circ}$ ). For all self-training cases the OW areas had a 

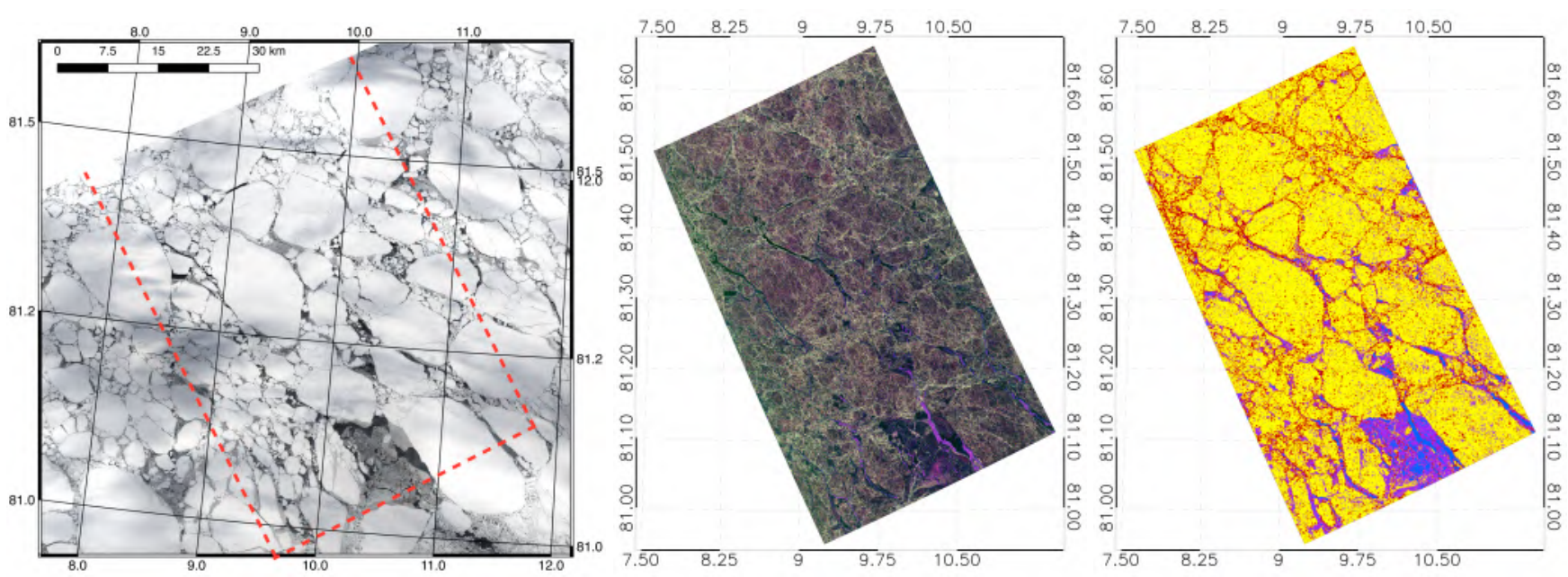

Fig. 1. Satellite images from the 24-25 May 2015. Left: Geocoded RGB composite of Landsat-8 on 24 May 2015. The approximate position of the ALOS-2 image is given by the red dashed line. Note that sea ice drift, primarily eastward, has occurred between the acquisition of the Landsat- 8 and the ALOS-2 images. Middle: Geocoded Pauli RGB composite (Red: HH-VV Green: HV+VH Blue: HH+VV) of the ALOS-2 acquisition on 25 May 2015 (IA: 39.05 ${ }^{\circ}$ ). Right: Classified ALOS-2 images from 25 May 2015, Open water/nilas (OW) blue, young ice (YI) purple, smooth first year ice (SFYI) yellow, rough first/multi year ice (RFMYI) red.

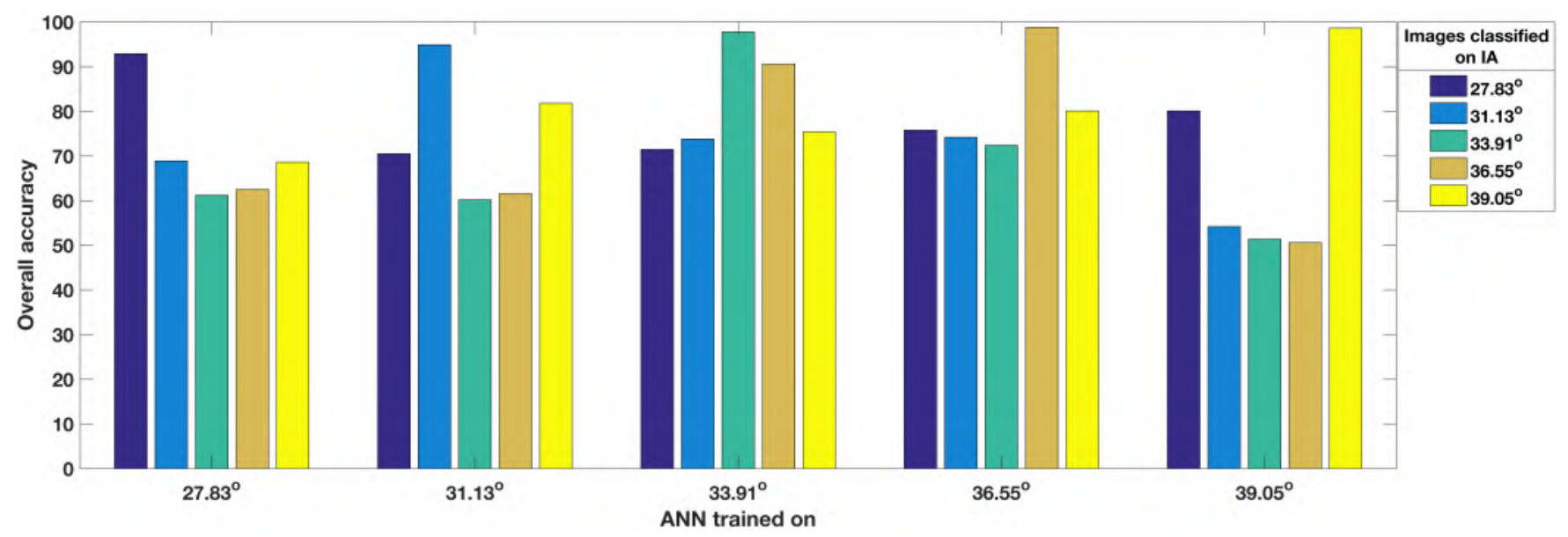

Fig. 2. Cross training/validation and overall classification accuracy across different IA

Table 2. Classification results compared to reference data samples from each class, for 3 April 2015 (left) and 18 May 2015 (right).

\begin{tabular}{|c|c|c|c|c|c|c|c|c|c|}
\hline \multicolumn{5}{|c|}{3 April 2015 (IA: $36.55^{\circ}$ ) } & \multicolumn{5}{|c|}{18 May 2015 (IA: $27.83^{\circ}$ ) } \\
\hline & & Referen & ice clas & & & & Referenc & ice cla & \\
\hline ANN Result & OW & YI & SFYI & RFMYI & ANN Result & OW & YI & SFYI & RFMYI \\
\hline OW & $100.0 \%$ & $0 \%$ & $0 \%$ & $0 \%$ & OW & $100.0 \%$ & $0 \%$ & $0 \%$ & $0 \%$ \\
\hline YI & $0 \%$ & $98.6 \%$ & $0 \%$ & $0 \%$ & YI & $0 \%$ & $95.3 \%$ & $0 \%$ & $0 \%$ \\
\hline SFYI & $0 \%$ & $0.9 \%$ & $98.9 \%$ & $2.2 \%$ & SFYI & $0 \%$ & $2.7 \%$ & $86.9 \%$ & $10.5 \%$ \\
\hline RFYMYI & $0 \%$ & $0.5 \%$ & $1.1 \%$ & $97.8 \%$ & RFYMYI & $0 \%$ & $2.0 \%$ & $13.1 \%$ & $89.5 \%$ \\
\hline
\end{tabular}


$100 \%$ accuracy and the YI areas have a high accuracy, the largest miss-classifications are a result of a mix up between smooth FYI (SFYI) and rough FYI/MYI (RFMYI). It was also observed that ANN trained with IA $33.91^{\circ}$ and $36.55^{\circ}$ performed relatively well across images acquired with different IA (Fig. 2).

We also compare the classification results achieved on the ALOS-2 scene with different incidence angle with spatially and temporally overlapping Landsat-8 scenes, one of the example of those validation is presented in (Figure 1). This ALOS-2 scene was not used for the extraction of the ROI's and therefore a visual validation of the classification results within each incidence angle group can be performed. We observe that the the sea ice classification produces satisfactory results when it comes to identifying the open water and the young ice areas. Areas classified as smooth FYI were observed in the Landsat- 8 images to correspond to smooth sea ice areas (first year ice floes with snow cover).

From the cross-trained-validation results we observe that accuracy is lower than for the self-trained-validation classification. This is not surprising as the backscatter values change with incidence angle as does the values for other polarimetric features. Though we observe that the open water and young ice areas are jointly correctly identified though sometimes misclassified as the other. The major ridges and deformed sea ice is also correctly identified. From this we conclude that even though the training data from the same incidence angle is preferential training data from another incidence angle can be used to classify sea ice in adjoining incidence angle scenes, though the difference in angle should if possible be kept to a minimum.

The incidence angle dependency has similar characteristic to the ones observed in [7, 8] for the winter season. In [7] the incidence angle dependency for different sea ice types in L-band SAR is presented, notably the slope for different deformation stages, smooth, deformed and rough sea ice for FYI is shown. The slope was found to be on average -0.21 for all the different types of FYI, though the deformed FYI have a slightly steeper slope (-0.29) than the rough FYI (-0.18). [8] similarly observed that the rough FYI had a shallower slope $(-0.14)$ than the smooth FYI $(-0.23)$. The average slope in this study was found to be -0.25 . The similarity in the dependence is interesting since the FYI studies includes sea ice from the Canadian Arctic [7], the European Arctic (this study) and the Japanese Arctic [8], possibly implying that cross-Arctic sea ice classifications adjustments are possible.

\section{CONCLUSIONS}

In this work, we conducted a thorough investigations on Lband fully polarimetric data set for sea ice classification for an operational environment. One of the major issues, i.e. incidence angle dependencies have been discussed. Within operational scenario we recommend that the L-band images should be acquired at moderate incidence angle $\left(30^{\circ}-37^{\circ}\right)$ and independently trained classifier should be used for winter and melt-seasons. Status of snow cover also plays a major role on the robustness of the classifier and planned to be studied in depth during the upcoming MOSAiC expedition.

\section{REFERENCES}

[1] M. Arkett, D. Flett, R. D. Abreu, P. Clemente-Colon, J. Woods, and B. Melchior, "Evaluating ALOS-PALSAR for Ice Monitoring - What Can L-band do for the North American Ice Service?" in IGARSS 2008 - 2008 IEEE International Geoscience and Remote Sensing Symposium, vol. 5, July 2008, pp. V - 188-V - 191.

[2] J. A. Casey, S. E. Howell, A. Tivy, and C. Haas, "Separability of sea ice types from wide swath $\mathrm{C}$ - and L-band synthetic aperture radar imagery acquired during the melt season," Remote Sensing of Environment, vol. 174, pp. $314-328,2016$.

[3] M. Dabboor, B. Montpetit, S. Howell, and C. Haas, "Improving sea ice Characterization in Dry Ice Winter Conditions Using Polarimetric Parameters from C- and L-Band SAR Data," Remote Sensing, vol. 9, no. 1270, 2017.

[4] M. A. Granskog, A. Rösel, P. A. Dodd, D. Divine, S. Gerland, T. Martma, and M. J. Leng, "Snow contribution to first-year and second-year Arctic sea ice mass balance north of Svalbard," Journal of Geophysical Research: Oceans, vol. 122, no. 3, pp. 2539-2549, 2017.

[5] R. Ressel and S. Singha, "Comparing Near Coincident Space Borne C and X Band Fully Polarimetric SAR Data for Arctic Sea Ice Classification," Remote Sensing, vol. 8, no. 1, p. 57, 2016.

[6] S. Singha, A. Johansson, N. Hughes, S. Munk Hvidegaard, and H. Skourup, "Arctic Sea Ice Characterization using Spaceborne Fully Polarimetric L-, C- and X-band SAR with Validation by Airborne Measurements," IEEE Transactions on Geoscience and Remote Sensing, vol. 56, no. 7, pp. 3715-3734, 2018.

[7] M. S. Mahmud, T. Geldsetzer, S. E. L. Howell, J. J. Yackel, V. Nandan, and R. K. Scharien, "Incidence Angle Dependence of HH-Polarized C- and L-Band Wintertime Backscatter over Arctic Sea Ice," IEEE Transactions on Geoscience and Remote Sensing, vol. 56, no. 11, pp. 6686-6698, 2018.

[8] H. Wakabayashi, T. Matsuoka, K. Nakamura, and F. Nishio, "Polarimetric characteristics of sea ice in the Sea of Okhotsk observed by airborne L-band SAR," IEEE Transactions on Geoscience and Remote Sensing, vol. 42, no. 11, pp. 2412-2425, 2004. 